\title{
Embryonic Cell Suspension Grafts in a Rat Model of Parkinson's Disease
}

\author{
P. Alvarez, K. de la Cuétera, J.C. García, O. Castellanos, L. Francis, R. Macias, \\ L. Bonet and M. MacPherson \\ Centro Iberolatinoamericano de Transplante y Regeneracion del Sistema Nervioso. \\ Ave 25 \# 15805 Playa, C. Habana, Cuba
}

Male Wistar rats were lesioned with 6hydroxydopamine in the right substantia nigra. Six weeks later motor disturbance was assessed by amphetamine- $(5 \mathrm{mg} / \mathrm{kg})$ induced rotation for $90 \mathrm{~min}$. Ten $\mu \mathrm{l}$ of cell suspension (300,000 cells) from the ventral mesencephalon of rat embryos or vehicle were injected into the denervated striatum of two groups: T II: transplant distributed in two sites of the same trace in dorsal striatum; T III: transplant distributed in three sites in a triangular fashion in the dorsal striatum. The amphetamine test was then repeated at 1, 3, 6, 12 and 23 weeks. The mean turns/min were reduced in the transplanted animals and showed significant differences at 6 weeks, while rotation was almost reduced to zero at 23 weeks. The recovery from the motor disturbance did not differ between groups T II and T III at any time. Rats receiving vehicle did not show any improvement in motor asymmetry. These results confirm and extend previous reports on the recovery from motor deficits seen in rats with unilateral DA-depletion that can be provided by fetal nigral grafts reinnervating the dorsal portions of the striatum /1,2/. All groups showed a significant difference in the levels of dopamine (DA), dihydroxyphenacetic acid (DOPAC), and homovanillic acid (HVA) when compared with normal animals. An increment in DA, DOPAC and HVA levels in dorsal striatum was detected in groups $\mathrm{T}$ II and $\mathrm{T}$ III in comparison with the control group; however, a significant difference was found only between $T$ III and the control group. A small increment of less than $1 \%$ of DA level in dorsal striatum was able to reverse the motor disturbance occurring after caudate-putamen denervation. DA, DOPAC and HVA levels in dorsal striatum tended to increase in group T III in comparison with group $\mathrm{T}$ II; however, there were no differences in behavioral recovery between these groups. This suggests that recovery from motor asymmetry may reveal neurotransmitter changes at very low levels. The higher neurotransmitter levels in the T III group could be induced by a higher cell survival rate or by an improved development of surviving cells as compared to the T II group. It is also possible that the three site transplants are more widely distributed so that metabolites are more easily detected.

Immunocytochemical studies showed tyrosine hydroxylase-immunoreactive neurons extending large fibres both within and outside the graft.

\section{Percentage of Dopamine and its metabolites in Transplanted and Control Groups.}

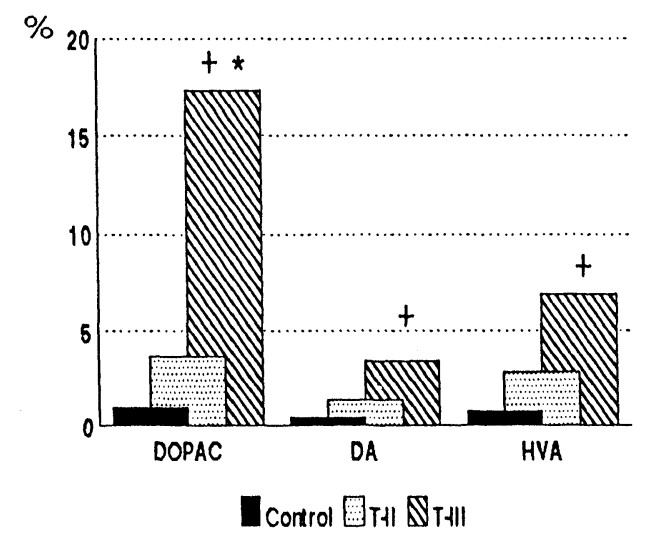

100\% represents level or Dopamine and its metabolites in normal rals. $+p<0.05$ (Kruskal Wallis lest) between T-1II and control. - $p<0.05$ (Kruskal Wallis (esi) between $T-11$ and $T-111$.

\section{Figure}

\section{REFERENCES}

Freed WJ et al. Ann Neurol 1980; 8: 810-819.

Nishino H. Brain Res 1990; 534: 83-93. 

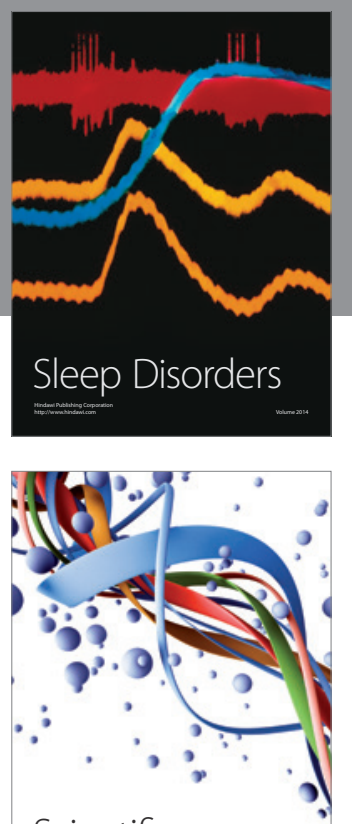

Scientifica
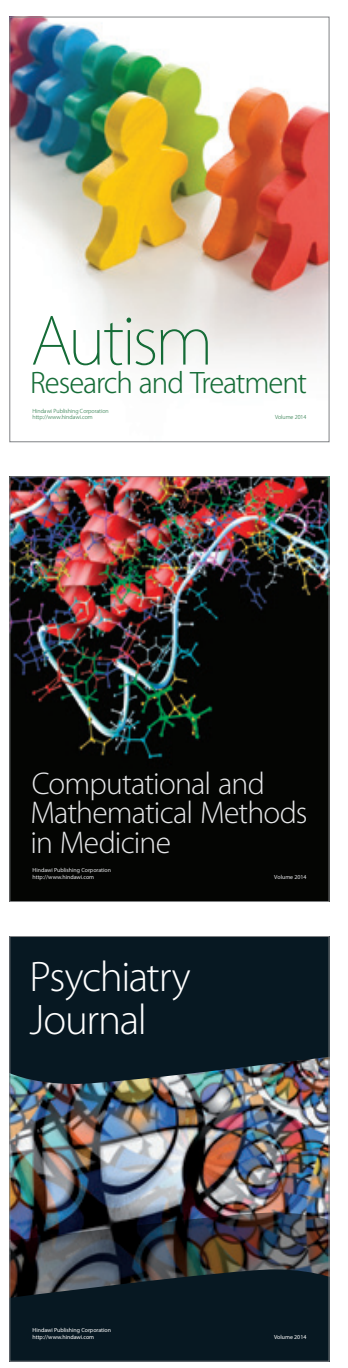
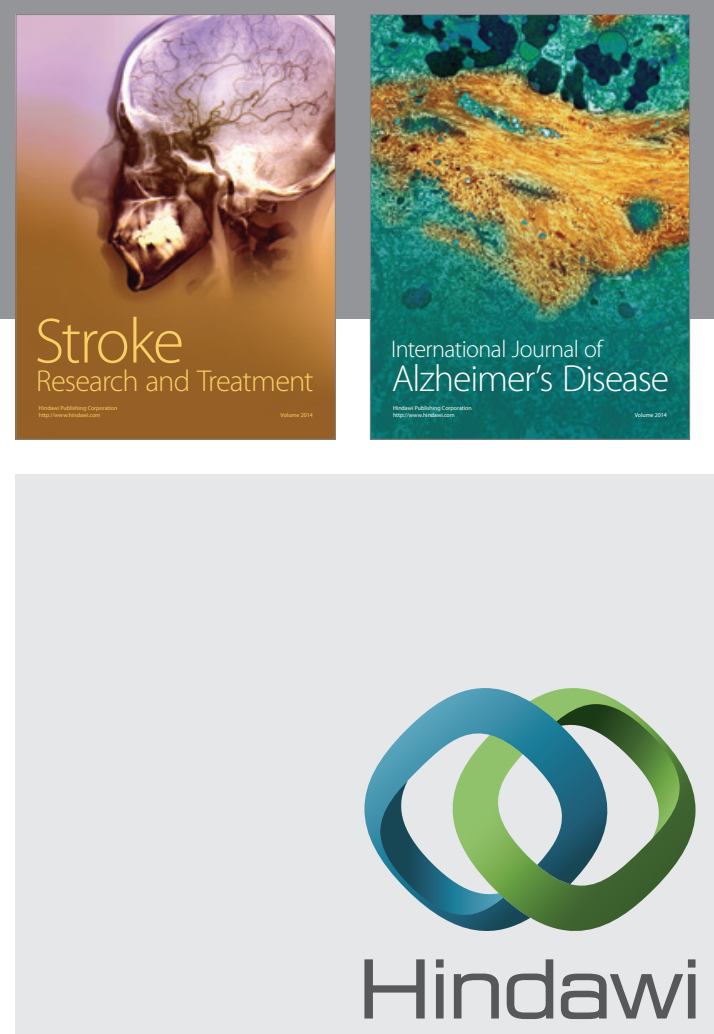

Submit your manuscripts at

http://www.hindawi.com
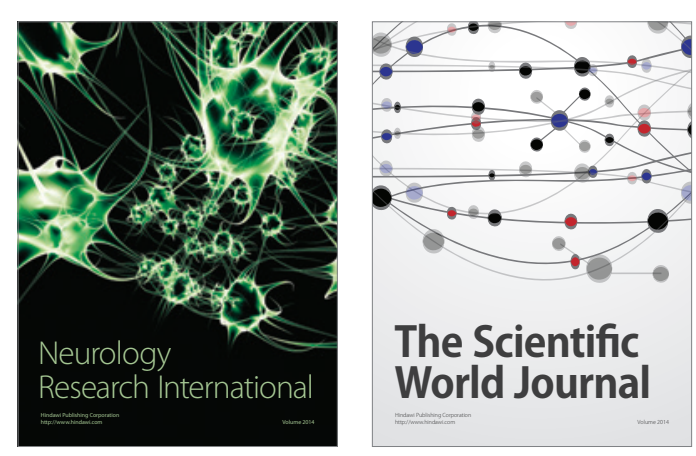

The Scientific World Journal

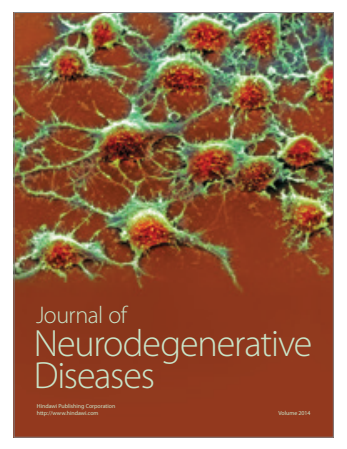

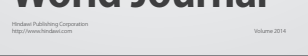

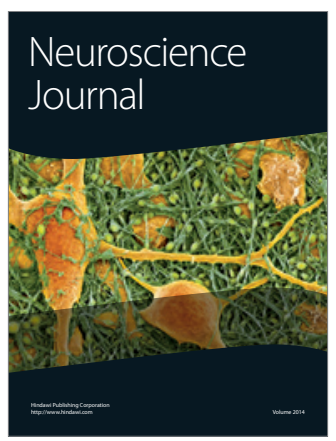

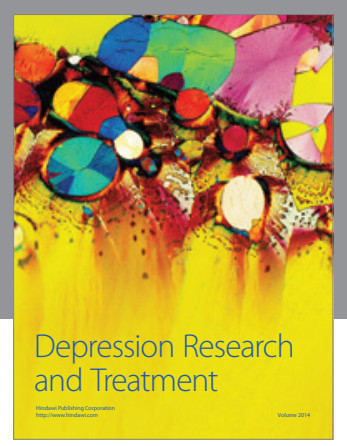
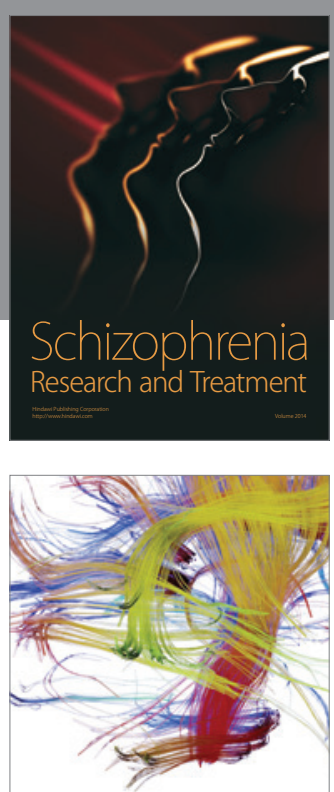

Brain Science

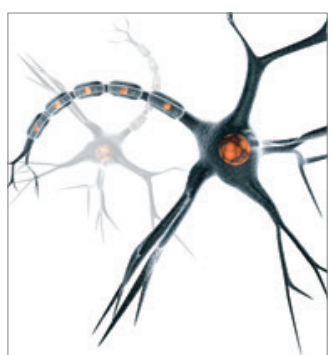

Neural Plasticity
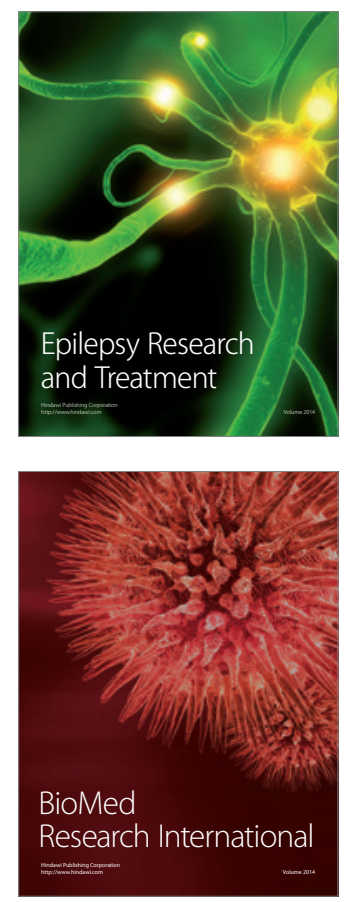

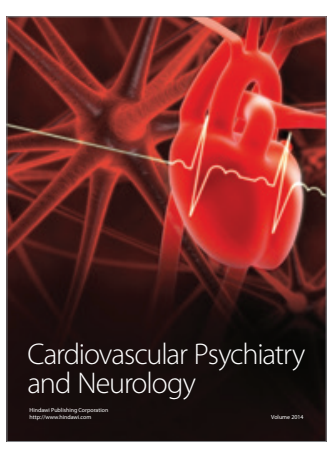

Parkinson's

Disease
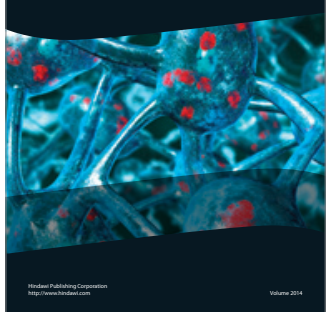